\title{
A RESPONSABILIDADE PÓS-CONTRATUAL NO DIREITO CIVIL ${ }^{1}$
}

\author{
Lissandra de Ávila Lopes ${ }^{2}$
}

\begin{abstract}
RESUMO: A responsabilidade pós-contratual, embora pouco difundida na doutrina e jurisprudência brasileiras, é de suma relevância quando o Poder Judiciário tem por finalidade a obtenção da justiça social. O presente trabalho foi embasado em pesquisas bibliográficas, com o objetivo de analisar a responsabilidade pós-contratual e sua aplicabilidade no Direito Civil diante da falta de disposição expressa sobre esse assunto no art. 422 do respectivo Código. Assim, o projeto de lei que atualmente tramita no Congresso Nacional é de vasta importância, pois além de pacificar grande parte da doutrina, dará ensejo a que decisões judiciais possam dar provimento às questões em que tenha ocorrido lesão patrimonial decorrente de atos praticados após a extinção do contrato.
\end{abstract}

PALAVRAS-CHAVE: Responsabilidade pós-contratual. Culpa Post Pactum Finitum. Boa-fé objetiva. Deveres acessórios.

ABSTRACT: The post-contractual responsibility, although it is little spread in the doctrine and Brazilian jurisprudence, it is of utmost relevance when the Judiciary Power has as purpose obtain social justice. The present work was based in bibliographical researches, and the objective was analyze the post-contractual responsibility and its applicance to the Civil Law before the lack of expressed disposition about this subject in the article 422 of the respective Code. Thus, the law project that currently moves in the National Congress is of utmost importance, because besides pacifying a great part of the doctrine, it will give opportunity to judicial decisions to be able to give provision to the subjects in which has happened patrimonial lesion in derivation of the acts that were practised after the extinction of the contract.

KEY WORDS: Post-contractual responsibility. Post Pactum Finitum Guilt. Objective Good-faith. Accessory Duties.

\section{INTRODUÇÃO}

A responsabilidade pós-contratual, tema do presente trabalho, tem sido pouco difundida pela doutrina e jurisprudência não só no Brasil, mas na maioria dos países com ordenamentos jurídicos influentes, a exceção da Alemanha e de Portugal, onde a culpa post pactum finitum tem suscitado relevantes contribuições doutrinárias e jurisprudenciais. No Brasil, embora aceita por parte da doutrina e dos tribunais, que ensejaram alguns julgados favoráveis à responsabilização pós-contratual, o novo Código Civil carece de uma regulamentação expressa sobre o assunto, o que se evidencia no art. 422.

Porém, tem-se como inconcebível que a legislação pátria não abranja as responsabilizações provenientes de atos que, após a conclusão do contrato, firam a boafé objetiva. Assim, a presente pesquisa tem como plano analítico a caracterização

\footnotetext{
${ }^{1}$ Artigo apresentado na disciplina de Teoria Geral dos Contratos
} 
aplicação da responsabilidade pós-contratual no Direito Civil brasileiro ante a falta de previsão expressa do art. 422 do novo Código Civil. Com embasamento em análises bibliográficas e jurisprudenciais, há o compromisso de dirimir as controvérsias mais relevantes acerca da caracterização da culpa post pactum finitum, suas justificativas e aplicabilidade.

Há, portanto, a necessidade de se fazer, preliminarmente, algumas distinções para que haja uma melhor compreensão do tema ao longo da leitura. Sendo assim, o trabalho será segmentado, em três partes: primeiramente, serão feitas algumas considerações sobre a responsabilidade pré-contratual e contratual; posteriormente, será realizado o estudo particularizado da responsabilidade pós-contratual; e, por fim, será examinado o art. 422 do Código Civil de 2002 e do projeto de lei relativo a esse dispositivo legal.

\title{
2. NOÇÕES ELEMENTARES ACERCA DAS RESPONSABILIDADES PRÉ- CONTRATUAL E CONTRATUAL
}

Importante se faz a distinção entre responsabilidade pré-contratual e contratual, ainda que não seja este o objetivo deste trabalho. A responsabilidade pré-contratual, também chamada de culpa in contrahendo, foi primeiramente positivada na Alemanha no ano de 1861 e, posteriormente, pelas legislações italiana, francesa, e portuguesa. No Brasil, grande parte da doutrina e da jurisprudência foram contrárias à sua adoção, que passou a ser admitida somente a partir das publicações do jurista Antônio Chaves em $1959^{3}$. Atualmente a doutrina brasileira recepciona a culpa in contrahendo através da aplicação dos princípios da liberdade contratual e da boa-fé decorrentes de negociações preliminares realizadas pelas partes. Fala-se em responsabilidade pré-contratual quando há um rompimento injustificado das tratativas. Fernando Noronha (2003) explica a ocorrência da responsabilidade pré-contratual:

\begin{abstract}
A parte que nas negociações preliminares procede deslealmente viola deveres que são impostos pelo princípio da boa-fé objetiva e que impõe a nãointerrupção injustificada das tratativas, a informação leal, o sigilo quanto a informações recebidas da contraparte e, em geral, a não indução desta em erro. Essa violação impede algumas vezes a realização do negócio; outras, justificam que este venha a ser invalidado. Tanto num caso como no outro,
\end{abstract}

\footnotetext{
${ }^{2}$ Acadêmica do $4^{\mathrm{o}}$ semestre do Curso de Direito da Universidade Federal de Santa Maria (UFSM) Email: zipliss@gmail.com

${ }^{3}$ DONINI, 2004, p. 52.
} 
quando a outra parte, com o propósito de se preparar para cumprir o esperado contrato, tiver sido levada a realizar despesas (seja com estudos, projetos e pesquisas, seja até com a aquisição de máquinas específicas ou de elevada quantidade de matéria-prima), ou a abster-se de contratar com outras pessoas, ou mesmo a deixar de realizar outros negócios, terá de ser indenizada. (NORONHA, 2003, p. 456)

Destarte, diante do princípio da boa-fé objetiva, tem-se como primordial que o causador da lesão ao patrimônio alheio responda pelos danos causados. Ressalte-se, ademais, que mesmo com a invalidação do contrato vindouro, ainda assim poderia haver uma responsabilidade pré-contratual.

A responsabilidade contratual, via de regra, não sofre objeções para que seja adotada pela doutrina e jurisprudência, sendo que, por vezes, o contrato é visto como uma lei estabelecida entre as partes. Por referir-se ao descumprimento de uma obrigação estabelecida interpartes, a responsabilidade contratual pode ser proveniente tanto dos contratos como dos atos unilaterais, como a promessa de recompensa, o pagamento indevido e a gestão de negócios (DONINI, 2004, p.22), desde que os requisitos de validade estejam presentes. Além disso, na responsabilidade contratual não há maiores dificuldades para se comprovar o descumprimento de uma obrigação capaz de gerar uma reparação e, nas relações de consumo, conforme dispões o Código de Defesa do Consumidor, sequer há a necessidade de comprovação da culpa para que haja uma reparação. Assim, nas relações consumeiras, havendo o inadimplemento comprovado da obrigação, o ônus da prova desloca-se para o devedor, que estará incumbido de provar a ausência de culpa ou a ocorrência de caso fortuito ou força maior.

Com isso, essencial se faz a distinção entre responsabilidade pré-contratual e contratual, uma vez que, enquanto na contratual, em regra, há muitas controvérsias acerca da responsabilização dos danos causados durante a execução e conclusão do contrato, na culpa in contrahendo segue-se uma gama de discussões em torno do seu caráter contratual ou extracontratual, bem como das situações de que decorrem a responsabilização. Este assunto será retomado ao longo do texto afim de proporcionar um maior esclarecimento não apenas sobre a responsabilidade pós-contratual, mas também, acessoriamente, sobre a responsabilidade pré-contratual.

Feitas as considerações acerca das responsabilidades pré-contratual e contratual, que são embasamentos para a compreensão da culpa post pactum finitum, passa-se à abordagem da responsabilidade pós-contratual, objetivo da presente pesquisa. 


\section{RESPONSABILIDADE PÓS-CONTRATUAL}

A responsabilidade pós-contratual, também chamada de culpa post pactum finitum, caracteriza-se pelo dever de responsabilização pelos danos advindos após a extinção do contrato, independentemente do adimplemento da obrigação. Pode-se dizer que a responsabilidade pós-contratual é uma projeção da responsabilidade précontratual, guardando-se as devidas particularidades.

A ocorrência da responsabilidade pós-contratual se dá quando há um descumprimento dos deveres acessórios, anexos dos deveres principais ${ }^{4}$ da relação contratual. Os deveres acessórios, criados pela doutrina e jurisprudência alemãs, são aqueles decorrentes da boa-fé dos contratantes, ou seja, são os deveres de lealdade, proteção e informação, previstos ou não em lei.

A ciência das dessemelhanças entre deveres principais, secundários e acessórios é de grande relevância pois permite o reconhecimento de uma verdadeira responsabilidade pós-contratual diante de outras formas de pós-eficácia obrigacional que, por vezes, podem causar confusão com a culpa post pactum finitum, tais como: a pós-eficácia aparente, a virtual, e a continuada. A pós-eficácia aparente é aquela em que uma das partes poderá responsabilizar a outra parte em decorrência de previsão expressa da lei, mesmo após a extinção do contrato. É o que ocorre, por exemplo, quando há, na compra-e-venda, o dever de garantia do produto, ou seja, quando o vendedor continua com o compromisso de garantir o bom funcionamento do produto vendido mesmo após o cumprimento do contrato devido à regulamentação do Código de Defesa do Consumidor. Trata-se, em razão da previsão legal, não de pós-eficácia, mas de eficácia obrigacional (CORDEIRO apud DONNINI, 2004, p.122). A pós-eficácia virtual é verificada quando há o cumprimento de deveres secundários ${ }^{5}$ após a extinção da obrigação principal, como acontece, a título exemplificativo, no dever de restituição (dever secundário) ocorrente após a extinção do contrato de locação (obrigação principal). Por fim, outra situação que muito se assemelha à responsabilidade póscontratual é a pós-eficácia continuada, que ocorre nas obrigações de execução continuada, como por exemplo, nas prestações. Assim, quando os deveres acessórios,

\footnotetext{
${ }^{4}$ Os deveres principais da relação contratual são aqueles indispensáveis para que a obrigação seja devidamente adimplida. É, por exemplo, na compra-e-venda, a entrega do bem. (DONINI, 2004, p.41.) ${ }^{5}$ Os deveres secundários, são aqueles que complementam a obrigação principal, e o seu descumprimento não acarreta o inadimplemento total, mas o cumprimento imperfeito da obrigação No caso do exemplo anterior, corresponde à entrega do bem em condições de limpeza.
} 
ou seja, os deveres de lealdade, proteção e informação persistem até que o contrato seja completamente cumprido, tem-se a pós-eficácia continuada, isto é, há pós-eficácia continuada quando os deveres acessórios do dever principal devem ser cumpridos apenas durante o cumprimento do contrato. Diferentemente ocorre na culpa post pactum finitum, em que a obrigação de cumprir os deveres acessórios não previstos em lei ou na tratativa persistem mesmo após a extinção do contrato. Salienta-se, novamente, que a pós-eficácia aparente, a virtual e a continuada não se enquadram na culpa post pactum finitum, ou seja, não podem ser chamadas de responsabilidade pós-contratual.

A responsabilidade pós-contratual fundamenta-se, sobretudo, no princípio da boa-fé objetiva ${ }^{6}$, que prima pelo agir conforme os padrões recomendados pela sociedade, ou seja, agir com lisura, correção e honestidade de modo a não frustrar a confiança dos demais contratantes. Conforme versa Rui Rosado Aguiar (apud MELO, 2004) a boa-fé objetiva é

um princípio geral de Direito, segundo o qual todos devem comportar-se de acordo com um padrão ético de confiança e lealdade. Gera deveres secundários de conduta, que impõem às partes comportamentos necessários, ainda que não previstos expressamente nos contratos, que devem ser obedecidos a fim de permitir a realização das justas expectativas surgidas em razão da celebração e da execução da avenca. (AGUIAR apud MELO, 2004)

Por se tratar de um princípio geral das relações contratuais, tem-se que a boa-fé objetiva é irrenunciável, e se dirige a todos os participantes da relação contratual, não apenas as credores e devedores. Além disso, a sua aplicação independe de orientação expressa da legislação, por tratar-se de princípio fundamental ${ }^{7}$.

Dada fundamentação da boa-fé objetiva, resta saber se a responsabilidade póscontratual configura-se como sendo contratual, extracontratual, ou de uma terceira via de responsabilidade. A responsabilidade contratual, abordada inicialmente, refere-se ao descumprimento de obrigação estabelecida entre as partes ou decorrente dos efeitos do contrato. Em contrapartida, a responsabilidade extracontratual refere-se à prática de um ato ilícito que cause prejuízo à outra parte, sem que haja, contudo, qualquer vínculo contratual entre as partes, sendo, por isso, de difícil comprovação, uma vez que cabe à

\footnotetext{
${ }^{6}$ Importante se faz distinguir a boa-fé subjetiva da boa-fé objetiva. A boa-fé subjetiva diz respeito ao estado de ignorância ou ao estado psicológico individual de cada uma das partes em relação ao contrato, como, por exemplo, ocorre quando uma das partes pensa ser portadora de um direito que na realidade não possui. Diferentemente, a boa-fé objetiva refere-se aos objetivos de lealdade e de confiança que se espera de toda a relação contratual (SAMPAIO, 2004).
} 
parte lesada comprovar, além do dano, a culpa e o nexo de causalidade entre ambos. A terceira via da responsabilidade civil, defendida por Menezes Leitão, mescla características das responsabilidades contratual e extracontratual, pois "existiria algo mais que a simples responsabilidade extracontratual, porém não se pode asseverar que haveria uma obrigação assumida pelas partes, ao menos no sentido técnico." (LEITÃO apud DONNINI, 2004, p. 147). Entretanto, a melhor teoria a ser adotada é a de que a responsabilidade pós-contratual insere-se no âmbito das responsabilidades contratuais, porquanto haverá, nesse caso, o inadimplemento dos deveres contratuais acessórios de lealdade, informação e proteção, continuando, portanto, o vínculo contratual em razão de persistirem também os efeitos do contrato $^{8}$. Isto é, a infringência dos deveres acessórios é resultado direto do contrato estabelecido entre as partes. Desta maneira, sendo contratual a culpa post pactum finitum, está será regida, obviamente, conforme as regras contratuais de responsabilização. Com isso, vê-se a importância da caracterização da responsabilidade pós-contratual para se tenha a possibilidade do exercício de um direito.

\subsection{Casos concretos abarcados pela jurisprudência estrangeira e nacional}

A primeira vez que um tribunal pôde apreciar uma situação concreta de uma responsabilização decorrente da culpa post pactum finitum foi em 1925, dez anos após o surgimento de doutrinário acerca do assunto. $\mathrm{O}$ caso foi de uma compra-e-venda de um terreno com uma bela vista para um monte, em que a compradora foi convencida pelo vendedor de que a bonita imagem vista do terreno jamais seria obstruída em decorrência de alguma edificação, pois o plano diretor da cidade impedia essa construção. Porém, meses após a negociação, o vendedor conseguiu modificar o plano diretor da cidade, tendo adquirido o terreno ao lado e construído uma edificação que retirou do terreno vendido a visão da paisagem que tanto motivou a negociação por parte da compradora. A autora, lesada pela incorreção do comportamento do vendedor conseguiu lograr vultuosa indenização no Tribunal de Revista alemão 9 .

Posteriormente, a jurisprudência alemã deparou-se com outros dois casos. Em um, houve a venda de casacos de pele idênticos para duas lojas vizinhas que,

\footnotetext{
${ }^{7}$ Nesse sentido, SILVA, AGUIAR JR, LOZ MOZOS e VARELA apud SAMPAIO, 2004, p. 40.

${ }^{8}$ Em contrapartida, o mesmo não se pode afirmar em relação à responsabilidade pré-contratual, uma vez que extinta a obrigação, cessam os efeitos do contrato. Nesse caso, tem-se a responsabilidade como sendo extracontratual.

${ }^{9}$ DONINI, 2004, p. 86.
} 
conseqüentemente, foram lesadas em razão da concorrência desleal. No outro caso, houve a venda de um tapete para um indivíduo que explorava um hotel. A loja indicou um terceiro para fazer a instalação do tapete, mas omitiu informações sobre o procedimento necessário para a correta instalação do tapete, danificando-o. No entanto, atualmente, em razão da vigência atual do Código de Defesa do Consumidor que expressamente regulamenta o dever de informação, esse caso não mais caracteriza a responsabilidade pós-contratual, mas insere-se no conceito de pós-eficácia aparente. Embora estes três exemplos tenham norteado toda a doutrina e jurisprudência acerca da culpa post pactum finitum, nos dias hoje, somente os dois primeiros casos exemplificam, de fato, uma responsabilidade pós-contratual, enquanto o último caso, ilustra a pós-eficácia aparente.

No Brasil, embora em menor escala, também há jurisprudências que abordam a responsabilidade pós-contratual. O Tribunal do Rio Grande do Sul, de maneira inovadora no Brasil, acolheu a teoria da responsabilidade pós-contratual fundamentada no princípio da boa-fé objetiva:

EMENTA: COMPRA E VENDA. RESOLUCAO. CULPA POST PACTUM FINITUM. O VENDEDOR QUE IMEDIATAMENTE APOS A VENDA TORNA INVIAVEL A COMPRADORA DISPOR DO BEM, AMEACANDO-A DE MORTE E A ESCORRACANDO DO LUGAR, PARA APROVEITAR-SE DISSO E VENDER A CASA PARA OUTREM, DESCUMPRE UMA OBRIGACAO SECUNDARIA DO CONTRATO E DA MOTIVO A RESOLUCAO. PRINCIPIO DA BOA FE. PRELIMINAR DE NULIDADE REJEITADA. APELO PROVIDO EM PARTE, APENAS PARA SUSPENDER EXIGIBILIDADE DOS ONUS DA SUCUMBENCIA. (Apelação Cível N 588042580, Quinta Câmara Cível, Tribunal de Justiça do RS, Relator: Ruy Rosado de Aguiar Júnior, Julgado em 16/08/1988)

Com isso, percebe-se que com o acolhimento dessas duas decisões, além de outras proferidas no mesmo sentido ${ }^{10}$, os Tribunais brasileiros, ainda que timidamente, tem adotado a responsabilidade pós-contratual como sendo medida de aplicação da eqüidade social. Porém, não se pode negar que a culpa post pactum finitum continua sendo escassamente adotada.

\section{APLICABILIDADE DA CULPA POST PACTUM FINITUM}

\footnotetext{
${ }^{10}$ STJ, REsp 132.265/RS, Recurso Especial n. 1997/0034802-4. Rel. Min. Aldir Passarinho Junior, $4^{\mathrm{a}}$ Turma, DJ 12-2-2001.
} 
A responsabilidade pós-contratual, conhecida por culpa post pactum finitum, tem pouquíssimo acolhimento pela jurisprudência brasileira, ainda que surjam cada vez mais doutrinadores que tratem do tema. As jurisprudências alemã e portuguesa são as que mais preocupam-se no tratamento da responsabilidade pós-contratual. Na Alemanha, em 1925, houve a primeira decisão em torno da culpa post pactum finitum, "quando o Reichsgericht (RG) decidiu que, após o término de uma cessão de crédito, o cedente deveria continuar a não impor obstáculos ao cessionário" (DONNINI, 2004, p. 86), e seguiram-se outros julgados no mesmo sentido. Porém, nem mesmo com a recepção desses julgados a responsabilidade pós-contratual conseguiu o mesmo êxito de acolhimento jurisprudencial e doutrinário que a responsabilidade pré-contratual obteve. Algumas das razões que justificam o pouco êxito da teoria pós-contratual encontram-se na escassez de casos concretos que realmente caracterizem essa responsabilidade, uma vez que a grande maioria das situações em que se pensa tratar de culpa post pactum finitum referem-se, na realidade, aos casos de pós-eficácia aparente, virtual ou continuada, conforme esclarecido anteriormente.

Outro suposto motivo propulsor do insucesso da responsabilidade pós-contratual é a dificuldade de se comprovar e fundamentar precisamente a ocorrência de um dano resultante do inadimplemento de deveres acessórios de boa-fé objetiva após o cumprimento ou a extinção do contrato. Ademais, frisa-se, também, que embora essas duas razões referidas justifiquem, de certo modo, a quase inutilização da responsabilidade post pactum finitum, uma terceira razão para não se acolher essa teoria é o comodismo de grande parte dos tribunais, que por vezes, preferem não reconhecer a responsabilidade, justificando-se pela extinção da obrigação juntamente com o contrato, a optar por um julgamento mais justo ao caso concreto, porém, obviamente, mais trabalhoso.

Com a finalidade de pacificar a recepção da responsabilidade pós-contratual no novo Código Civil, foi que ao Dep. Ricardo Fiúza enviou-se o texto do Projeto de Lei n. 6.960/2002, formulado segundo as reflexões do jurista Antônio Junqueira de Azevedo, com vistas a modificar o disposto no art. 422 do $\mathrm{CC} / 02$. A redação seria a seguinte:

Art. 422. Os contratantes são obrigados a guardar, assim nas negociações preliminares e conclusão do contrato, como em sua execução e fase póscontratual, os princípios da probidade e boa-fé e tudo mais que resulte da 
natureza do contrato, da lei, dos usos e das exigências da razão e da eqüidade (FIÚZA, 2005, p. 377).

Embora, o paradigma do "juiz boca da lei" tenha sido superado, vê-se que a modificação do art.422 do CC/02 é de grande utilidade para que se tenha uma adoção legislativa expressa da responsabilidade pós-contratual que irá otimizar o julgamento de casos concretos dispostos nesse sentido. Sabe-se que a culpa post pactum finitum, mesmo sem regulamentação expressa, tem sido empregada pelos tribunais. Todavia, a sua adoção tem sido ínfima ante a falta de previsão legal, e a gama de juristas que se posicionam contra a responsabilidade pós-contratual.

Alegam esses juristas que, admitindo-se a responsabilidade pós-contratual, haveria um atentado à segurança dos negócios jurídicos e uma subjetividade muito grande por parte do julgador. No entanto, tais argumentos não prosperam. Primeiramente, a violação de deveres acessórios ou anexos não é de difícil verificação, pois, conforme visto anteriormente, trata-se de inadimplemento dos deveres de proteção, lealdade ou informação. Em segundo lugar, a decisão do juiz, conforme disposição do art. 93, IX, da Constituição federal, deve ser sempre fundamentada, razão essa que inibe qualquer subjetividade do juiz. Além disso, sabe-se a efetiva segurança jurídica somente se dá após a decisão fazer coisa julgada, pois mesmo normas aparentemente claras podem ensejar interpretações diversas por parte dos julgadores.

\section{CONSIDERAÇÕES FINAIS.}

A responsabilidade pós-contratual mostra-se de grande importância e aplicabilidade às relações contratuais que se estabelecem na sociedade. Resultante de inadimplemento de deveres acessórios de proteção, lealdade e informação que permanecem após a conclusão ou extinção do contrato entre as partes, a culpa post pactum finitum, como também é chamada, classifica-se como sendo de cunho contratual, pois o inadimplemento se dá em razão dos efeitos do contrato.

Apesar da constatação de alguns julgados dando procedência à responsabilidade pós-contratual, esta tem sido pouco aplicada no Brasil e no mundo. As justificativas para tanto encontram-se no fato de não serem abundantes os casos concretos que realmente caracterizam a culpa post pactum finitum. A outra justificativa aceitável é a dificuldade de comprovação da violação de deveres acessórios que alguns juristas 
encontram. Porém, essa dificuldade se dá justamente em razão da pouca difusão dessa teoria. Ademais, vê-se que, como terceira justificativa para a pouca aplicabilidade da responsabilidade pós-contratual está assentada no comodismo existente em alguns tribunais, que preferem indeferir o pedido da parte lesada, através da argumentação de extinção do contrato e de qualquer vínculo obrigacional, à acolher o pedido e proferir uma decisão mais elaborada, justa e em consonância com os princípios da equidade e boa-fé.

Nesse ínterim, é que surge a proposta legislativa de modificação do art. 422 do Código Civil. A expectativa é de que, com uma previsão expressa, os tribunais brasileiros venham a acolher com muito menos objeções a culpa post pactum finitum, uma vez que muitos justificam a sua não aplicabilidade em decorrência de falta de previsão legal. De fato, o Código Civil carece de previsão expressa acerca desse tema, mas a Constituição Federal e os princípios fundamentais do Direito dão completo embasamento para que hoje, mesmo sem a previsão expressa, aplique-se essa teoria. Além disso, demais argumentos, como a insegurança jurídica e a subjetividade do julgador também devem ser rechaçados. A utilização da boa-fé objetiva para adimplemento da obrigação antes, durante e após o conclusão do contrato jamais devem servir de escopo para que se impeça o estabelecimento da justiça e equidade sociais.

\section{REFERÊNCIAS BIBLIOGRÁFICAS}

AZEVEDO, Antônio Junqueira de. O princípio da boa-fé nos contratos. Disponível em: 〈http://www.cjf.gov.br/revista/numero9/artigo7.htm>

DALLEGRAVE NETO, José Affonso. Contrato de trabalho. Ex-empregado difamado por patrão pode exigir indenização. Disponível em:

<http://conjur.estadao.com.br/static/text/25649,1> Acesso em: 20 fev. 2007.

DONNINI, Rogério Ferraz. Responsabilidade pós-contratual no novo Código Civil e no Código de Defesa do Consumidor. São Paulo: Saraiva, 2004.

ELESBÃO, Elsita Collor. Princípios Informativos das Obrigações Contratuais

Civis. Porto Alegre: Livraria do Advogado, 2000.

FIÚZA, Cezar. Novo Código Civil Comentado. $4^{\mathrm{a}}$ ed. São Paulo: Saraiva, 2005. p.3767.

FIÚZA, Cezar. Para uma releitura da teoria geral da responsabilidade civil.

Disponível em: < 
http://sisnet.aduaneiras.com.br/lex/doutrinas/arquivos/responsabilidade.pdf> Acesso em: 18 fev. 2007.

NORONHA, Fernando. Direito das obrigações: fundamentos do direito das obrigações: introdução à responsabilidade civil. Volume 1. São Paulo: Saraiva. 2003, pág. 456.

SAMPAIO, Laerte Marrone de Castro. A boa-fé objetiva na relação contratual. São Paulo: Manole, 2004.

TARTUCE, Flávio. O Princípio da Boa-fé Objetiva em Matéria Contratual. Apontamentos em Relação ao Novo Código Civil e Visão do Projeto no 6.960/02. Disponível em: < http://www.flaviotartuce.adv.br/secoes/artigos/artigo-boaf\%C3\%A9TARTUCE.doc> Acesso em: 18 fev. 2007.

VENOZA, Silvio de Savio- A boa-fé contratual no novo Código Civil. Disponível em: <http://www.societario.com.br/demarest/svboafe.html> Acesso em: 19 fev. 2007. 